\title{
Effect of images in six sense modalities on detection of visual signal from noise*
}

\author{
SYDNEY JOELSON SEGAL and VINCENT FUSELLA \\ Center for Research in Cognition and Affect \\ City University of New York, 33 West 42 St., New York, N.Y. 10036
}

Ss were asked to generate images in six different sense modalities, and a visual display was presented while they were imaging. The display consisted of a geometric pattern, and a small dim colored figure was present within the pattern on half the trials. Ss' ability to detect the figure was compared in the imaging task and in a standard discrimination task without imagery. Sensitivity $\left(d^{\prime}\right)$ was significantly poorer during imaging than during discrimination, was worse during visual imagery than during imagery of auditory, olfactory, gustatory, tactile, or kinesthetic objects, and was worse with images of relatively unfamiliar items. This phenomenon seems due to selective attentional effects.

It has been shown that when an $\mathrm{O}$ is generating an auditory image, his sensitivity $\left(d^{\prime}\right)$ for an auditory signal is reduced, while his visual image interferes with his ability to detect a visual signal (Segal \& Fusella, 1970). This was especially surprising, since the signal was exposed for 2 sec, a very long period in which there is ample opportunity for the $\mathrm{O}$ to switch his attention from the image to the signal.

There were, however, certain minor flaws in the procedure which were corrected in the present design. In this experiment, the detection task concerned only the detection of a visual signal, so the $O$ did not have the problem of channel switching which was present in the earlier signal detection task. A constant display of visual "noise" was introduced, which further ensured attentiveness to the visual channel and also controlled for random effects. Detection accuracy was compared in a standard or nonimaging condition, in the imaging condition where the $O$ was asked to generate images that were predominantly visual, and also in five nonvisual modalities: auditory, olfactory, gustatory, tactile, or kinesthetic.

\section{METHOD}

Two small Promaster 100-W projectors were used. The first projector contained the background "noise"-several zigzag lines of neutral gray; the second projector projected the stimulus-three horizontal blue bars of unequal lengths, in a triangular array resembling a fir tree. Placement of the projectors ensured that the blue bars appeared at about the center of the pattern of zigzag lines when both were present. The lamp in the stimulus projector was attenuated by a Powerstat voltmeter. A motor-driven

*This research was supported by AFOSR Contract No.F44620-68-C-0093. These experiments were presented to the Psychonomic Society at the October 1969 meetings. timer was used (Industrial Timing); at a manual signal, it projected either one or both projectors for $2 \mathrm{sec}$. The noise of the control timer clearly signaled the onset of the display whether one or both projectors were activated, but the projectors themselves were silent.

The pattern and signal were back-projected onto a $20-\mathrm{cm}$ screen of translucent plastic, which formed the end of a plastic cylinder or eyepiece, $35 \mathrm{~cm}$ in length. The screen subtended a visual angle of about $19 \mathrm{deg}$, the zigzag lines, $15 \mathrm{deg}$, and the signal at its widest point, 6 deg.

Twenty 17- and 18-year-old men and women served as paid $S s$, each serving for three 2 -h sessions. $S$ was seated in a comfortable chair, could look through the cylinder at the screen, and was instructed that on each trial the E would say, "Ready," and that then the pattern would appear. He should search the pattern to determine if the blue figure was also present. Intensity was maintained at a level where $S$ made about $15 \%-20 \%$ errors.

After 40-50 practice trials, there were 100 discrimination trials, half with the pattern alone, half with the blue figure as well. Then $S$ was asked to image different items. He was instructed not to give any verbal report, but to raise his hand as soon as he "had" an image. At this point, the pattern was projected; the signal was also present on half the trials. As soon as the display was effaced, the $O$ reported whether or not he detected the signal. There were 128 imaging trials, and the 128 images were varied both for sense modality and familiarity of the images. There were 64 visual images, 32 auditory, 8 olfactory, 8 gustatory, 8 tactile, and 8 kinesthetic; half were familiar, half were unfamiliar.

The experimental session closed with a second discrimination task, also of 100 trials.

The second and third sessions were virtually the same as the first; a different list of 128 images was used in each session.

\section{RESULTS}

Sensitivity $\left(d^{\prime}\right)$ was poorer during imaging than discrimination and, within the imaging task, relatively poorer with visual than with nonvisual images and with unfamiliar than with familiar images.

Sensitivity scores $\left(d^{\prime}\right)$, comparing the means of the normalized distributions for reception of signal plus noise and noise alone (Freeman, (1964), were virtually identical for first and second discrimination tasks (2.67 and 2.63), indicating that Os were responding at a stable level. During the intervening imagery session, however, sensitivity fell to 1.99 , a significant decline $(G=12.36$, $\mathrm{p}<.001)$ as measured by the $G$ statistic (Gourevitch \& Galanter, 1967). Taken separately, there was a significant difference between visual imagery and discrimination $(G=12.86, \quad p<.001)$, between auditory imagery and discrimination $(G=5.14, p<.001)$, and between all other imagery and discrimination $(\mathrm{G}=6.46, \mathrm{p}<.001)$.

Within the imaging session, sensitivity was lowest when Os were imaging visual items, higher for imagery in all other sensory modalities (see Table 1). It is impressive that there was so little variation among the five other sense modes, and no significant differences were found. Sensitivity for visual images differed significantly from $d^{\prime}$ for auditory images $(G=4.24, p<.001)$ and also from $d^{\prime}$ for all other sensory modes combined $(G=3.19, p<.001)$. As the number of trials with each of the four other nonauditory sensory modes was rather meager (240 with signal, 240 without), statistical comparison of visual images with these four was somewhat unreliable; nevertheless, it was found that visual images differed significantly from olfactory and kinesthetic images $(G=2.70$ and 2.43 , $\mathrm{p}<.01$ ), but not from tactile or gustatory $(\mathrm{G}=1.14$ and $1.13, \mathrm{p}=13)$.

Familiarity of the items imaged was

Table 1

Hit and False Alarm Frequencies, $d$ and $\beta$ Values, Visual Noise Experiment

\begin{tabular}{lccc}
\hline & Hit/fa & $\mathrm{d}^{\prime}$ & $\beta$ \\
\hline Discrimination & & & \\
$\quad$ First & $.82 / .040$ & 2.67 & $\mathbf{3 . 0 5}$ \\
$\quad$ Second & $.82 / .043$ & 2.63 & 2.87 \\
$\quad$ Imaging Total & $.77 / .105$ & 1.99 & 1.67 \\
Visual & $.76 / .130$ & 1.85 & 1.50 \\
Auditory & $.79 / .078$ & 2.23 & 1.98 \\
Olfactory & $.80 / .075$ & 2.28 & 1.98 \\
Gustatory & $.77 / .100$ & 2.02 & 1.73 \\
Tactile & $.78 / .108$ & 2.01 & 1.60 \\
Kinesthetic & $.77 / .067$ & 2.24 & 2.34 \\
\hline
\end{tabular}


also a significant variable. The difference in sensitivity between familiar and unfamiliar images was significant $(G=5.59, p<.001)$. For the visual images, there was an especially great difference between the $\mathrm{d}^{\prime}$ of 2.10 during imagery of familiar items and the $d^{\prime}$ of 1.61 while imaging unfamiliar items $(G=5.13, p<.001)$. There was also a difference between sensitivity for familiar and unfamiliar items in the auditory mode $\left(d^{\prime}=\mathbf{2 . 4 5}\right.$ and 2.06, $\mathrm{G}=2.58, \mathrm{p}<.01$ ) and the olfactory mode $\left(d^{\prime}=2.91\right.$ and 1.92 , $\mathrm{G}=2.91, p<.01$ ), but not for the other sensory modes. As in a previous experiment (Segal \& Fusella, 1970), familiarity seemed to be a more reliable variable when the image and the signal were in the same sensory mode.

Criterion or beta (Freeman, 1964) was lower during the imaging task (due especially to the increased frequency of false alarms) than for either the first or second discrimination (Wilcoxon signed-ranks test $=2.56$ and 2.74 , respectively, $\mathbf{p}<.01$ ). Criterion was also slightly less conservative during visual than during nonvisual imagery.

Signal detection theorists assume that the $d^{\prime}$ remains constant as long as there is a constant signal, constant noise, and constant receiver. The present data confirm that our effects occurred within the receiver, and they can most parsimoniously be explained as due to the influence of selective attention (see Treisman, 1969). It seems that the $O$ first orients himself within a specific sensory modality and then that channel is primarily oriented toward either internal or external input. During construction of a visual image, the receiver's visual analyzers are biased toward internal input, and a concurrent visual signal is not fully analyzed and therefore inadequately detected. During construction of an auditory or tactile image, the visual analyzers are relatively free and the visual signal is more adequately processed. There also seems to be some general influence of central attention, which may explain both the fact that there is some decrement in sensitivity for the visual signal during nonvisual imagery and also the finding of a difference according to the familiarity of the item imaged. The shift in criterion suggests that Ss try to compensate for shifting their attention internally by lowering the criterion for external signals.

\section{REFERENCES}

FREEMAN, P. R. Table of $d^{\prime}$ and $\beta$. Medical Research Council, Applied Psychology Research Unit, Cambridge, England, 1964.

GOUREVITCH, V., \& GALANTER, E. A significance test for one parameter isosensitivity functions. Psychometrika. $1967,32,25-33$.

GREEN. D. M.. \& SWETS. J. A. Signal detection theory and psychophysics. New York: Wiley, 1966.

SEGAL, S. J., \& FUSELLA, V. Influence of imaged pictures and sound on detection of visual and auditory signals. Journal of Experimental Psychology, 1970, 83, 458-464.

TREISMAN, A. M. Strategies and models of selective attention. Psychological Review, 1969, 76, 282-299.

\section{CURRENT LITERATURE ON VISION}

BAUMSTIMLER, Y., \& PARROT; J. (Université Laval, Cité Universitaire, Québec 10è, P.Q., Canada). Stimulus generalization and spontaneous blinking in man involved in a voluntary activity. Journal of Experimental Psychology, 1971, 88, 95-102.

COHEN, G. (Institute of Experimental Psychology, University of Oxford, Oxford, England). Differential effects of irrelevant dimensions in three shape recognition tasks. British Journal of Psychology, 1971, 62, 151-156.

CUMMING, G. (Institute of Experimental Psychology, Oxford, England). LINC-8 presents and controls visual experiments. Behavior Research Methods \& Instrumentation, 1971, 3, 24-29.

GRONWALL, D. M. A. (University of Auckland, Auckland, New Zealand), \& SAMPSON, H. Ocular dominance: $A$ test of two hypotheses. British Journal of Psychology, 1971, 62, 175-185.

HERMELIN, B. M. (MRC Developmental Psychology Unit, Gordon Street, London, England),
\& O'CONNOR, N. Children's judgements of duration. British Journal of Psychology, 1971, 62, 13-20.

McGLAUGHLIN, A. (University of Hull, Hull England), \& DALE, H. C. A. Stimulus similarity and transfer in long-term paired-associate learning. British Journal of Psychology, 1971, 62, 37-40.

SEKULER, R. (Northwestern University, Evanston, Dl. 60201), \& ARMSTRONG, R. Luminance control of a small computer CRT display: A very cheap technique. Behavior Research Methods \& Instrumentation, 1971, 3, 48-49.

SIEGEL, M. H. (Albion College, Albion, Mich. 49224), and SIEGEL, A. B. A comparison of techniques for measuring hue appearance. Behavior Research Methods \& Instrumentation, 1971, 3, 1.4.

SPERLING, G. (Bell Telephone Laboratories, Murray Hill, N.J. 07974). The description and luminous calibration of cathode ray oscilloscope visual displays. Behavior Research Methods \& Instrumentation, 1971, 3, 148-151.
SPERLING, G. (Bell Telephone Laboratories, Murray Hill, N.J. 07974 ). Flicker in computer-generated visual displays: Selecting a CRO phosphor and other problems. Behavior research Methods \& Instrumentation, 1971, 3, 151-153.

SPERLING, G. (Bell Telephone Laboratories, Murray Hill, N.J. 07974). Stereoscopic visual displays: Principles, viewing devices, alignment procedures. Behavior Research Methods \& Instrumentation, 1971, 3, 154-158. WEINTRAUB, D. J. (University of Michigan, Ann Arbor, Mich. 48104). Rectangle discriminability: Perceptual relativity and the law of Prägnanz. Journal of Experimental Psychology, 1971, 88, 1-11.

WINTERS, J. J. (Research Department, E. R. Johnstone Training and Research Center, Bordentown, N.J. 08505), \& BALDWIN, D. Development of twoand three-dimensional size constancy under restricted cue conditions. Journal of Experimental Psychology, 1971, 88, 113-118. 